\title{
Avaliação microbiológica e físico-química de leites UHT produzidos no Estado do Paraná - Brasil
}

\section{Evaluation of microbiological and physical-chemical quality of UHT milk produced in the Parana State - Brazil}

\author{
Luciano dos Santos Bersot ${ }^{*}$; Júlia Arantes Galvão ${ }^{2}$; \\ Nelson Kodama Lançoni Raymundo ${ }^{3}$; Vinicius Cunha Barcellos ${ }^{1}$; \\ José Paes Almeida Nogueira Pinto ${ }^{4}$; Maike Taís Maziero ${ }^{5}$
}

\section{Resumo}

\begin{abstract}
No presente trabalho foram analisadas 150 amostras de leite UHT integral de três marcas comercializadas em Palotina, entre outubro de 2004 e fevereiro de 2005. Foram realizadas contagens de bactérias mesófilas aeróbicas, sendo os resultados comparados aos padrões estabelecidos pelo Regulamento Técnico de Identidade e Qualidade (RTIQ) para leite UHT do Ministério da Agricultura, Pecuária e Abastecimento do Brasil. Entre as amostras analisadas, 36 (24\%) apresentaram contagem de mesófilos acima da legislação. Também foram realizadas análises físico-químicas destas amostras, sendo que 7,3\% dos resultados de acidez titulável, $29 \%$ de gordura e 50,7\% de extrato seco desengordurado estavam em desacordo com o RTIQ. Todas as amostras estavam dentro dos padrões para as análises de índice crioscópico e estabilidade em álcool.
\end{abstract}

Palavras-chave: Leite UHT, qualidade, físico-química, mesófilos

\begin{abstract}
The present work analyzed 150 UHT whole milk samples from three different brands, commercialized in city of Palotina (Paraná, Brazil), between October of 2004 and February of 2005. Mesophilic aerobic bacteria counting results were compared to the Agriculture Ministry of Brazil official standards (RTIQ) for UHT milk. 36 (24\%) of the sample presented higher mesophilic bacteria counting according to the standards. Also, were proceeded physic-chemical analyses of those samples. $7.3 \%$ of the acidity results, $29 \%$ of crude fat and $50.7 \%$ of dry matter without fat were disagreeing to RTIQ. All samples accorded to the standards for cryoscopy and alcohol stability tests.
\end{abstract}

Key words: UHT Milk, quality, physic-chemical, mesophilic

\footnotetext{
1 Prof. Dr., Universidade Federal do Paraná - UFPR, Campus de Palotina, PR. E-mail: lucianobersot@ufpr.br Prof. MSc., Universidade Federal do Paraná - UFPR, Campus de Palotina, PR. E-mail: vcbarcellos@ufpr.br

2 Acadêmico Curso de Medicina Veterinária, Universidade Federal do Paraná - UFPR, Campus Palotina, PR. E-mail: juliagalvaomv@yahoo.com.br

3 Médico Veterinário autônomo. E-mail: nel_mv@hotmail.com

4 Professor Dr. Associado, Universidade Estadual de São Paulo, FMVZ, UNESP, Campus de Botucatu, SP. E-mail: josepaes@, fmvz.unesp.br

5 Doutoranda em Tecnologia deAlimentos, Universidade Federal do Paraná-UFPR, PPGTA, Curitiba, PR. E-mail:maikemaziero@ yahoo.com.br

* Autor para correspondência
} 


\section{Introdução}

$\mathrm{O}$ leite se constitui num alimento muito rico ao ser avaliado nutricionalmente, composto por $87,3 \%$ de água e $12,7 \%$ de sólidos totais, distribuídos da seguinte forma: proteínas totais, 3,3 a 3,5\%; gordura, 3,5 a 3,8\%; lactose, 4,9\%; minerais, $0,7 \%$ em média, além de vitaminas. Por ser altamente nutritivo, o leite pode se tornar um excelente meio de cultura para microrganismos deteriorantes e patogênicos (SGARBIERI, 2005).

O leite UAT (ultra-alta temperatura) ou UHT (ultra hight temperature) é o leite homogeneizado, submetido durante 2 a 4 segundos a uma temperatura de $130^{\circ} \mathrm{C}$, mediante processo térmico de fluxo continuo, imediatamente resfriado a uma temperatura inferior a $32^{\circ} \mathrm{C}$ e envasado sob condições assépticas em embalagens estéreis e hermeticamente fechadas (BRASIL, 1996).

O Regulamento Técnico de Identidade e Qualidade (RTIQ) para leite UAT (UHT) do Ministério da Agricultura, Pecuária e Abastecimento do Brasil (BRASIL, 1996) estabelece o mínimo de $3 \%$ de gordura para o leite integral, acidez titulável entre 0,14 e $0,18 \%$ de ácido lático, estabilidade ao etanol $68 \%$ e, no mínimo, $8,2 \%$ de extrato seco desengordurado (ESD). Após a incubação da embalagem fechada por 7 dias a $35-37^{\circ} \mathrm{C}$, nenhuma amostra deve apresentar-se com contagem de aeróbios mesófilos superior a $10^{2} \mathrm{UFC} / \mathrm{mL}$ em um lote de 5 amostras.

A qualidade do leite cru tem efeito direto na qualidade e vida útil do leite UHT (GILLIS et al., 1985). No Brasil, o leite cru tem se mostrado frequentemente em desacordo com os padrões microbiológicos (NERO et al., 2005; PINTO; MARTINS; VANETTI, 2006; ARCURI et al., 2006) e físico-químicos brasileiros (LORENZETTI et al., 2006; MENDONÇA, 2001; MARTINS et al., 2008).

Estudos sobre a qualidade do leite UHT indicam que alguns esporos podem sobreviver ao tratamento térmico apesar do processo destruir todas as células bacterianas vegetativas (ROSENTHAL, 1991). Sendo assim, o leite UHT nem sempre é um produto livre de contaminações, podendo, portanto, sofrer deterioração. A baixa qualidade microbiológica do leite, além de ser um problema de saúde pública altera tanto as características sensoriais quanto a vida útil dos produtos lácteos (FRANCO; LANDGRAF, 1996).

O leite UHT tem uma participação elevada na comercialização de leites fluídos no Brasil devido, principalmente, a sua praticidade e vida de prateleira. Segundo dados da Associação Brasileira de Leite Longa Vida (ABLV, 2009), a participação de mercado do produto que era de 9,6\% em 1992, alcançou 74,8\% em 2008.

A expansão do leite UHT no mercado brasileiro pode ser explicada pela sua vida útil prolongada, o que viabiliza sua logística, assim como por não exigir refrigeração, sendo mais cômodo para o consumidor (SANTOS; MARTINS; TEIXEIRA; 1999).

No entanto, no Brasil, apesar da crescente importância desse produto no mercado, poucos são os trabalhos relacionados à qualidade do leite UHT. O presente trabalho teve como objetivo avaliar a qualidade microbiológica e físico-química de marcas de leites UHT produzidas no Estado do Paraná, Brasil.

\section{Material e Métodos}

Foram avaliadas 150 amostras de três marcas de leite UHT integral identificadas como X, Y e Z, produzidas em fábricas de laticínios localizadas no Estado do Paraná, entre outubro de 2004 e fevereiro de 2005. De cada marca foram coletadas 50 amostras divididas em cinco lotes, portanto dez amostras por lote; destas, cinco foram incubadas a $35-37^{\circ} \mathrm{C}$ por 7 dias e cinco analisadas no dia da coleta.

As análises microbiológicas foram realizadas conforme recomendado pelo Regulamento Técnico de Identidade e Qualidade (RTIQ) do leite UHT, 
estabelecido pela Portaria 146 do Ministério da Agricultura e Pecuária (BRASIL, 1996).

A contagem de mesófilos aeróbios foi realizada por semeadura em ágar padrão para contagem, seguida de incubação a $36^{\circ} \mathrm{C}$ por $48 \mathrm{~h}$, segundo a Instrução Normativa 62 (BRASIL, 2003) e os resultados expressos em UFC/mL. A partir das contagens obtidas, para triagem, três colônias de microrganismos aeróbios mesófilos isolados em cada amostra foram selecionadas e submetidas a provas tintoriais pelo método de Gram, para classificação dos microrganismos através da morfologia e coloração.

As análises físico-químicas (densidade, acidez titulável, teor de gordura, índice crioscópico, estabilidade ao etanol $68 \%$, teores de extrato seco total e desengordurado) foram realizadas segundo LANARA (BRASIL, 1981).

Todas as análises foram realizadas no Laboratório de Pesquisa em Microbiologia e Físico-Química de Alimentos da Universidade Federal do Paraná - Campus de Palotina. Os resultados obtidos foram avaliados comparando-se com os valores de referência descritos no RTIQ de leite UHT.

\section{Resultados e Discussões}

Das 150 amostras analisadas, $36 \quad(24 \%)$ apresentaram contagem de mesófilos aeróbios acima do padrão estabelecido pela RTIQ para leite UHT ( $10^{2}$ UFC/mL) (Tabela 1). Estes resultados foram inferiores aos encontrados por Coelho et al. (2001) em Belo Horizonte - MG, que detectaram $41,2 \%$ das 80 amostras de leite UHT com contagens de mesófilos aeróbios acima do limite estabelecido pelo RTIQ; e também inferiores aos resultados encontrados por Rezende et al. (2000) em Ribeirão Preto-SP, onde 53,3\% das 120 amostras de leite UHT de quatro marcas comerciais comercializadas em Ribeirão Preto-SP apresentaram contaminação por microrganismos mesófilos.

Vidal-Martins et al. (2005) avaliaram 110 amostras de leite UHT de 11 marcas diferentes comercializadas em São José do Rio Preto-SP e encontraram $22,7 \%$ das amostras fora do padrão, com contagens de microrganismos heterotróficos mesófilos variando de $<1,0 \times 10^{2} \mathrm{UFC} / \mathrm{mL}$ a $\geq 1,0 \times$ $10^{6} \mathrm{UFC} / \mathrm{mL}$. Outro estudo feito com 100 amostras de leite UHT de diferentes regiões do Brasil revelou um total de $45 \%$ de amostras com contagens acima do limite tolerável pelo RTIQ oscilando entre 2,0 x $10^{4}$ e $9,5 \times 10^{5} \mathrm{UFC} / \mathrm{mL}$ (ZACARCHENCO et al., 2000).

A presença de mesófilos aeróbios no leite UHT pode ser indicativa da má qualidade do leite cru, condições inadequadas de armazenamento e processamento ou contaminação pós-processamento (WESTHOFF, 1981).

A marca $\mathrm{Z}$ foi a que apresentou os piores resultados onde $62 \%$ das amostras apresentaram-se com contagens superiores ao limite regulamentar, seguido de X e Y, com $6 \%$ e 4\%, respectivamente (Tabela 1).

Quanto aos resultados observados na coloração de Gram, nas amostras analisadas da marca X, houve predominância de cocos Gram-positivos $(66,7 \%)$, seguida por $27,8 \%$ de cocos Gramnegativos, 5,5\% para bacilos Gram-negativos. Para a marca $Y$, também ocorreu predominância de cocos Gram-positivos (57,9\% das amostras). Contudo, para a marca $Z$ houve certo equilíbrio de isolamento entre cocos Gram-positivos, cocos Gram-negativos e bacilos Gram-negativos (Figura 1). Esta marca foi a que apresentou maior percentual de amostras fora do padrão microbiológico, sendo que tal fenômeno pode estar relacionado à diversidade morfológica encontrada. 
Tabela 1. Número de amostras com contagem de mesófilos $(\mathrm{UFC} / \mathrm{mL})$ acima do estabelecido pela Portaria 146 do Ministério da Agricultura (BRASIL, 1996) (limite máximo de $100 \mathrm{UFC} / \mathrm{mL}$ ).

\begin{tabular}{|c|c|c|c|}
\hline \multirow{2}{*}{ Marca } & \multicolumn{2}{|c|}{ Número de amostras fora do padrão } & \multirow{2}{*}{$\begin{array}{l}\text { Total de amostras fora } \\
\text { do padrão }(\%)\end{array}$} \\
\hline & Sem incubação & Incubadas a $35-37^{\circ} \mathrm{C} / 7$ dias & \\
\hline $\mathbf{X}$ & $0 / 25$ & $3 / 25$ & 6 \\
\hline $\mathbf{Y}$ & $2 / 25$ & $0 / 25$ & 4 \\
\hline $\mathbf{Z}$ & $15 / 25$ & $16 / 25$ & 62 \\
\hline Total & $17 / 75$ & $19 / 75$ & 24 \\
\hline
\end{tabular}

Dados do autor.

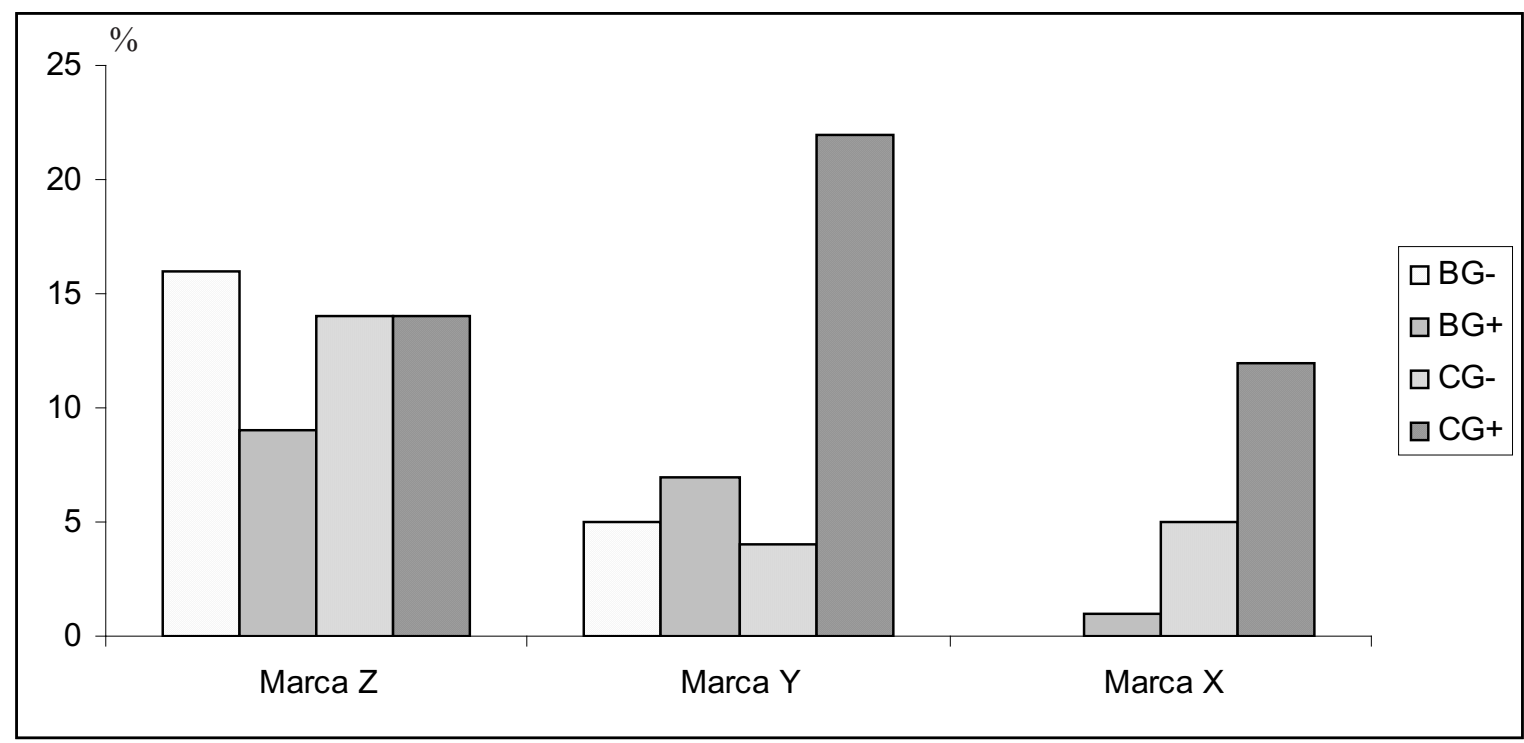

$\mathrm{B}=$ bacilos $; \mathrm{C}=\operatorname{cocos} ; \mathrm{G}-=$ Gram-negativo $; \mathrm{G}+=$ Gram-positivo

Figura 1. Resultados dos testes de Gram em porcentagem por marca.

Coelho et al. (2001) selecionaram 174 colônias para identificação morfológica e todas foram identificadas como Gram-positivas, sendo 1,7\% cocos e o restante bastonetes. A presença de cocos Gram-positivos, além de outros microrganismos, inclusive bacilos Gram-negativos, é descrita na literatura internacional por diferentes autores que afirmam ter o leite UHT uma microbiota originada de falhas durante o processamento e envase ou por recontaminações (SCHAAL; NOECKER, 1977; ID; SCHAAL, 1979; LEE, 1984).

Os problemas relacionados ao leite UHT também podem ser atribuídos a microrganismos termorresistentes formadores de esporos, principalmente do gênero Bacillus, que sobrevivem ao processo UHT (HUEMER et al., 1998; ZACARCHENCO et al., 2000).

Os resultados das análises físico-químicas estão apresentados na Tabela 2. Para as 150 amostras analisadas, 4,3\% dos resultados de densidade, 7,4\% dos resultados de acidez titulável, $29 \%$ dos resultados do teor de gordura e $50,7 \%$ dos resultados de ESD estavam em desacordo com a Portaria 146. Não houve diferença nos resultados físico-químicos nas amostras incubadas a $35-37^{\circ} \mathrm{C}$ por 7 dias quando comparadas às amostras analisadas sem incubação. 
Tabela 2. Número de amostras por marca que apresentaram alguma análise físico-química em desacordo com o padrão estabelecido pela legislação*

\begin{tabular}{cccccc}
\hline & \multicolumn{5}{c}{ Análises $^{1}$} \\
\hline \multirow{2}{*}{ Marca } & \multirow{2}{*}{ Densidade } & \multicolumn{2}{c}{ Acidez titulável } & \multirow{2}{*}{ Teor de Gordura } & \multirow{2}{*}{ Teor de ESD } \\
\cline { 3 - 4 } & & Abaixo & Acima & & \\
\hline $\mathbf{X}$ & $01(2 \%)$ & - & $2(4 \%)$ & $5(10 \%)$ & $23(46 \%)$ \\
$\mathbf{Y}$ & $03(6 \%)$ & $3(6 \%)$ & - & $38(77 \%)$ & $43(86 \%)$ \\
$\mathbf{Z}$ & 0 & $1(2 \%)$ & $5(10 \%)$ & 0 & $09(18 \%)$ \\
\hline Total & $04(2,7 \%)$ & $4(2,7 \%)$ & $7(4,7 \%)$ & $44(29 \%)$ & $76(50,7 \%)$ \\
\hline
\end{tabular}

* As provas do Álcool e Índice crioscópico estiveram dentro dos padrões legais

${ }^{1}$ Densidade a $15^{\circ} \mathrm{C}$ : mínimo $1,028 \mathrm{~g} / \mathrm{mL}$; Acidez titulável: mínimo 0,14\% e máximo 0,18\% ácido lático; Teor de gordura: mínimo de 3\%; Teor de ESD: mínimo de 8,2\%

${ }^{2}$ Resultados abaixo de $0,14 \%$ e acima de $0,18 \%$ de ácido lático.

Arruda et al. (2007) encontraram 10\% dos resultados de acidez titulável e do teor de gordura e 100\% dos resultados de ESD das 100 amostras de leite UHT avaliadas no Rio de Janeiro em desacordo com o RTIQ.

As trinta amostras de leite UHT analisadas por Martins et al. (2008) em um laticínio de São Paulo estavam de acordo com os parâmetros de acidez titulável e gordura estabelecidos pelo RTIQ, porém, com relação ao ESD, nenhuma das amostras atendeu ao estabelecido. Os autores relacionaram o baixo ESD a um aumento no teor de água, tendo em vista que o índice crioscópico também apresentou resultados alterados. No entanto, no presente estudo, todas as amostras apresentaram-se dentro dos padrões para a o índice crioscópico.

Analisando os resultados obtidos por marca avaliada, a marca $\mathrm{X}$ apresentou $46 \%, 10 \%$ e $2 \%$ dos resultados dos teores de extrato seco desengordurado (ESD), teor de gordura e densidade, respectivamente, abaixo do mínimo estabelecido pela legislação. Em duas amostras a acidez titulável foi de 0,19\% de ácido lático. A marca Y apresentou 86\%, 77\% e $6 \%$ dos resultados de ESD, gordura e densidade, respectivamente, abaixo do mínimo estabelecido pela legislação. Em 03 amostras os resultados de acidez titulável variaram de 0,11 a $0,13 \%$ de ácido lático podendo ser indicativo de neutralização da acidez titulável por agentes alcalinos. Na marca Z, $18 \%$ dos resultados de ESD apresentaram-se abaixo do mínimo. Em 10\% das amostras, a acidez titulável encontrada foi de 0,19 e em $2 \%, 0,13 \%$ de ácido lático. Notadamente, os teores de ESD e gordura foram os que estiveram abaixo do mínimo.

Todas as amostras das três marcas estavam dentro dos padrões para as análises de índice crioscópico e estabilidade em álcool. Estes dados coincidem com os encontrados por Silva (2004) em amostras de leite UHT comercializados em São Paulo, Rio Grande do Sul e Goiás. O autor sugere que o conservante citrato de sódio que é adicionado ao produto pode ter influência no resultado do índice crioscópico, uma vez que diminui o ponto de congelamento do leite. No entanto, o Regulamento Técnico de Identidade e Qualidade para leite UHT não estabele parâmetro de qualidade para este quesito.

\section{Conclusão}

Apesar da importância comercial e nutricional que o leite UHT desempenha no mercado brasileiro, podem ser encontradas irregularidades técnicas neste produto, quando comparados resultados de análises microbiológicas e físico-químicas aos padrões da legislação vigente. 


\section{Referências}

ASSOCIAÇÃO BRASILEIRA DE LEITE LONGA VIDA - ABLV. São Paulo: [s.n.], 2009. Disponível em: $<$ http://www.ablv.org.br/Estatisticas.aspx $>$. Acesso em: 02 set. 2009.

ARCURI, E. F.; BRITO, M. A. V. P.; BRITO, J. R. F.; PINTO, S. M.; ÂNGELO, F. F.; SOUZA, G. N. Qualidade microbiológica do leite refrigerado nas fazendas. Arq. Bras. Med. Vet. Zootec., Belo Horizonte, v. 58, n. 3, p. 440-446, 2006.

ARRUDA, P. M.; CRUZ, A. G.; ZOELLNER, S. S.; SILVA, R.; SOARES, M. M.; FERNANDES, V. S.; GALVÃO, A. P. G. L. K. Características físico-químicas do leite pasteurizado tipo $\mathrm{C}$ e leite ultra alta temperatura comercializados na cidade do Rio de Janeiro. Rev. Inst. Adolfo Lutz, Juiz de Fora, v. 66, n. 2, p.126-129, 2007.

BRASIL. Ministério da Agricultura. LANARA. Métodos analíticos oficiais para controle de POA e seus ingredientes: II - Métodos físicos e químicos. Brasília, DF, 1981.

BRASIL. Ministério da Agricultura e do Abastecimento. Portaria 146 de 07/03/1996. Regulamento Técnico de Identidade e Qualidade de Leite UAT. Brasília, DF: [s.n.], 1996.

BRASIL. Ministério da Agricultura Pecuária e Abastecimento. Instrução normativa $n^{\circ} 62$ de agosto de 2003. Métodos Analíticos oficiais para análises microbiológicas para controle de produtos de origem animal e água. Brasília, DF, 2003.

COELHO, P. S.; SILVA, N.; BRESCIA, M. V.; SIQUEIRA, A. P. Avaliação da qualidade microbiológica do leite UAT integral comercializado em Belo Horizonte. Arq. Bras. Med. Vet. Zootec., Belo Horizonte, v. 53, n. 2, p. 1-7, 2001.

FRANCO, B. D. G. M.; LANDGRAF, M. Microbiologia dos alimentos. São Paulo: Ed. Atheneu, 1996. 182 p.

GILLIS, W. T.; CARTLEDGE, M. F.; RODRIGUES, I. R.; SUAREZ, E. J. Effect of raw milk quality on ultra-high temperature processed milk. J. Dairy Sci., Champaign, v. 68, n. 68, p. 2875-2879, 1985.

HUEMER, I. A.; KLIJN, N.; VOGELSANG, H. W. J.; LANGEVELD, L. P. M. Thermal death kinetics of spores of Bacillus sporothermodurans isolated from UHT milk. Int. Dairy Journal, Alberta, v. 8, n. 10, p. 851-855, 1998.

ID, D.; SCHAAL, E. Microbiology of milk. Arch. Lebensmittlhyg, Praendl, v. 30, n. 1, p. 17-19, 1979.
LEE, C. M. Spoilage microorganism encountered in ultra high temperature processed milk. Chin. J. Microbiol. Imm., Zhonghua, v. 17, n. 2, p. 86-91, 1984.

LORENZETTI, D. K.; BAGGIO, E. C. R.; FONTOURA, P. S. G.; FREITAS, R. J. S. Avaliação físico-química de leite tipo $\mathrm{C}$ comercializado em Curitiba e região metropolitana. Hig. Aliment., São Paulo, v. 20, n. 138, jan./fev. 2006.

MARTINS, A. M. C. V.; ROSSI JÚNIOR, O. D.; SALOTTI, B. M.; BÜRGER, K. P.; CORTEZ, A. L. L.; CARDOZO, M. V. Efeito do processamento UAT (Ultra Alta Temperatura) sobre as características físicoquímicas do leite. Ciênc. Tecnol. Aliment., Campinas, v. 28, n. 2, p. 295-298, 2008.

MENDONÇA, A. H. Qualidade físico-química de leite cru resfriado: comparação de diferentes procedimentos e locais de coleta. Rev. Inst. Lat. Cand. Tostes, Belo Horizonte, v. 56, n. 321, p. 276-281, 2001.

NERO, L. A.; MATTOS M. R.; BELOTI, V.; BARROS, M. A. F.; PINTO, J. P. A. N.; ANDRADE, N. J.; SILVA, W. P.; FRANCO, B. D. G. M. Leite cru de quatro regiões leiteiras brasileiras: perspectivas de atendimento dos requisitos microbiológicos estabelecidos pela Instrução Normativa 51. Ciênc. Tecnol. Aliment., Campinas, v. 25, n. 1, p. 191-195, jan./mar. 2005.

PINTO, C. L. O.; MARTINS, M. L.; VANETTI, M. C. D. Qualidade microbiológica de leite cru e isolamento de bactérias psicrotróficas proteolíticas. Ciênc. Tecnol. Aliment., Campinas, v. 26, n. 3, p. 645-651, jul./set. 2006.

REZENDE, N. C. M.; ROSSI JÚNIOR, O. D.; NADER FILHO, A..; AMARAL, L. A.. Ocorrência de microrganismos indicadores em leite UHT ("ultra-hightemperature") milk. R. Bras. Cienc.Vet., Niterói, v. 7, n. 1, p. 58-60, jan./abr. 2000.

ROSENTHAL, I. Milk and dairy products: properties and processing. Weinheim, New York: VCH Publishers Inc., 1991.

SANTOS, C. V.; MARTINS, R. S.; TEIXEIRA, S. R. Leite longa vida no Brasil: alterações da rede logística e expansão do mercado. Disponível em: <http://www. anpad.org.br/enanpad/1999/dwn/enanpad1999-ols-15. pdf $>$. Acesso em: 13 ago. 2009.

SCHAAL, E.; NOECKER F. Investigation of the microbial quality of commercial UHT milk products. Arch. Lebensmittlhyg, Praendl, v. 28, n. 3, p. 56-61, 1977. 
SGARBIERI, V. C. Revisão: propriedades estruturais e físico-químicas das proteínas do leite. Braz. J. Food Technol., Campinas, v. 8, n. 1, p. 43-56, jan./mar. 2005.

VIDAL-MARTINS, A. A.; ROSSI JÚNIOR, O. D.; REZENDE-LAGO, N. C. Microrganismos heterotróficos mesófilos e bactérias do grupo Bacillus cereus em leite integral submetido a ultra alta temperatura. Arq. Bras. Med. Vet. Zoot., Belo Horizonte, v. 57, n. 3, p. 396-400, 2005.
WESTHOFF, D.C. Microbiology of ultra high temperature milk. J. Dairy Sci., Champaign, v. 64, n. 1, p. $167-173,1981$.

ZACARCHENCO, P. B.; LEITÃO, M. F. F.; DESTRO, M. T.; ANDRIGHETO, C. Ocorrência de Bacillus sporothermodurans em leite UAT/UHT brasileiro e a influência do tratamento térmico. Ciênc. Tecnol. Aliment., Campinas v. 20, n. 3, p. 271-178, 2000. 
